\title{
Endovascular closure of patent foramen ovale: a critical appraisal of published trials
}

\author{
Fechamento endovascular do forame oval patente: análise crítica dos estudos publicados
}

Charles ANDRÉ1,2

\begin{abstract}
The treatment of cryptogenic stroke patients with a patent foramen ovale (PFO) is controversial. A critical review of these studies is presented. Methods: A description of all trials comparing medical and endovascular treatment with closing devices is given. Additional pertinent studies are discussed to help construct a rational basis for treatment decisions. Results: Initial negative trials evaluating PFO closure were followed by positive studies published in 2017 and 2018. All trials evaluated young patients (up to 60 years). Methodological problems are present in all trials including their open label construction. Most positive trials developed strategies to increase the percentage of patients with interatrial septal aneurysms or hypermobility and large right-to-left shunts. Even in these positive trials, large numbers of patients need to be treated to avoid one stroke. Atrial fibrillation occurred in 2-6\% and other adverse effects related to the procedure and to the devices occurred in a substantial number of patients. Incomplete occlusion of the PFO is also frequent. Anticoagulant treatment has not been adequately studied as a therapeutic option. Conclusion: Young patients with cryptogenic strokes seem to benefit from endovascular closure of a PFO in the presence of a large right-to-left shunt or an associated atrial septum aneurysm. For most other patients, a highlyindividualized decision must be made, taking into account the low risk of recurrence in patients with a cryptogenic stroke attributable to a PFO, the high numbers needed to treat and the risks related to the procedure.
\end{abstract}

Keywords: Foramen ovale; patent; therapeutics; septal occluder device; stroke, prevention and control.

\section{RESUMO}

O tratamento de pacientes com infarto cerebral criptogênico e forame oval patente (FOP) é controverso. Uma revisão crítica destes estudos é apresentada. Métodos: São descritos em detalhes os estudos comparando tratamento médico com o uso de próteses de oclusão do FOP após infarto cerebral. Discutem-se outros estudos pertinentes para ajudar na tomada racional de decisões terapêuticas individualizadas. Resultados: Estudos iniciais avaliando fechamento endovascular com próteses foram negativos, porém seguidos de outros estudos com resultados positivos em 2017 e 2018. Somente pacientes até 60 anos foram estudados. Os estudos apresentam vários problemas metodológicos, incluindo sua natureza aberta. A maioria dos estudos positivos desenvolveu estratégias para aumentar o percentual de pacientes com risco aumentado de recorrência, especificamente grandes shunts direita-esquerda e aneurismas/hipermobilidade do septo interatrial. Mesmo estes estudos positivos revelaram um alto NNT (número de pacientes tratados para evitar um evento de desfecho). Fibrilação atrial ocorreu em 2-6 \% dos pacientes tratados. Outras complicações relacionadas ao procedimento e às endopróteses e ainda fechamento incompleto do FOP foram também frequentes. Anticoagulantes poderiam constituir estratégia alternativa de tratamento clínico, mas não foram adequadamente estudados. Conclusão: Pacientes jovens com infartos criptogênicos parecem beneficiar-se de oclusão endovascular do FOP na presença de grandes shunts e principalmente aneurismas ou hipermobilidade de septo interatrial. Para a maioria dos outros pacientes, uma decisão altamente individualizada deve ser tomada, considerando o baixo risco de recorrência dos infartos atribuíveis ao FOP, o ato NNT e os riscos inerentes ao procedimento.

Palavras-chave: Forame oval; patente; terapêutica; dispositivo para oclusão septal; Acidente vascular cerebral, prevenção e controle.

The best treatment for most stroke patients in whom a patent foramen ovale (PFO) is found remains undefined. Recent clinical trials support the use of sealing endoprostheses to reduce stroke recurrence rates in patients with no other definable causes and with a large right-to-left shunt (RLS), atrial septum aneurysm (ASA) or hypermobility of the interatrial septum. New data generated by these studies have also led to an epidemic of systematic reviews and meta-analyses on the subject. In this article, previous negative trials and the most recent and positive trials leading to renewed interest in PFO closure are reviewed. A discussion to help guide rational therapeutic decisions follows.

${ }^{1}$ Universidade Federal do Rio de Janeiro, Faculdade de Medicina, Disciplina de Neurologia, Rio de Janeiro RJ, Brasil;

²Sinapse Neurologia e Reabilitação, Rio de Janeiro RJ, Brasil.

Charles André (iD) https://orcid.org/0000-0001-8081-5741

Correspondence: Charles André; Rua Visconde de Pirajá, 4114 / sala 821; 22410-002 Rio de Janeiro RJ, Brasil; E-mail: dr.charles.andre@gmail.com

Conflict of interest: There is no conflict of interest to declare.

Received 06 December 2018; Received in final form 15 May 2019; Accepted 26 June 2019. 


\section{WHY PFO BECAME RELEVANT}

Tissue oxygenation in fetal life depends entirely on oxygen-rich blood flow from the placenta. An ample interatrial communication allows the oxygenated blood to bypass the immature and useless pulmonary circulation. The gradual development of the interatrial septum guarantees the future closure of this physiological shunt ${ }^{1,2}$ (Figure).

After birth, there is a natural tendency for spontaneous closure of the foramen ovale. This process is completed in $50 \%$ of two-year-old infants and in $65 \%$ of persons by the age of $20^{2,3}$. One quarter (26\%) of adult individuals, however, still have a detectable passage of blood between the two atria ${ }^{2-4}$. Other anatomical variants of potential clinical importance are less frequent. Atrial septum aneurysms or interatrial septum hypermobility (e.g., displacement of the septum $15 \mathrm{~mm}$ or more during the cardiac cycle) are present in $2-10 \%$ of individuals with a PFO. The Eustachian valve of the inferior vena cava (which can help drive blood to the left atrium through a PFO) and atrial Chiari networks (which may rarely cause entrapment of atrial catheters) are even rarer variants ${ }^{5}$.

A PFO is entirely asymptomatic in most individuals, but may be important in specific settings. Closure of a PFO may be needed in professional divers and in medical conditions such as orthostatic dyspnea/cyanosis syndrome ${ }^{3,6}$. Its significance in patients with migraine has been amply studied ${ }^{7}$. A PFO is also occasionally found in patients with systemic embolism.
Ischemic stroke constitutes the most frequent condition in which PFO closure is considered. In this setting, a PFO is a common finding, detected in approximately $42 \%$ (21-63\%) of patients with cryptogenic and non-cryptogenic cerebral infarcts. A PFO is more frequently found in patients with cryptogenic stroke than in those with a defined cause, however, with an odds ratio (OR) of 6 (95\% confidence interval (CI), 3.72-9.68) in patients up to 55 years of age ${ }^{8}$. The prevalence of ASA is also increased, especially in individuals with $\mathrm{PFO}$. The OR in older patients was found to be more heterogeneous but is also increased $-2.26(95 \% \mathrm{CI}, 0.96-5.31)^{8}$. A more recent epidemiological registry including 439 patients over 60 years (mean age 70) confirms a persistent association in older patients - OR 2.06 (95\%CI, 1.32-3.23) and also indicates an increased risk in the presence of a large RLS 9

Patent foramen ovale may be associated with cerebral infarcts by diverse mechanisms, including paradoxical embolism, arrhythmias and local stasis and thrombosis. The most frequent mechanism is paradoxical (venous-arterial) embolism. This may cause 4-5\% of all cerebral infarcts ${ }^{10}$. Detached clots from the venous system are usually trapped in the pulmonary circulation but can reach the systemic arterial system via PFO or other RLS, such as pulmonary fistulas. Thrombi usually form in the lower limbs but can also be found in pelvic veins. Twenty percent or more of patients with an acute cryptogenic cerebral infarct exhibit either deep vein thrombosis in the legs and pelvis or potentially-significant anatomic variants favoring its development, such as the May Turner compression of the iliac vein by the iliac artery ${ }^{11,12}$. Pelvic venous
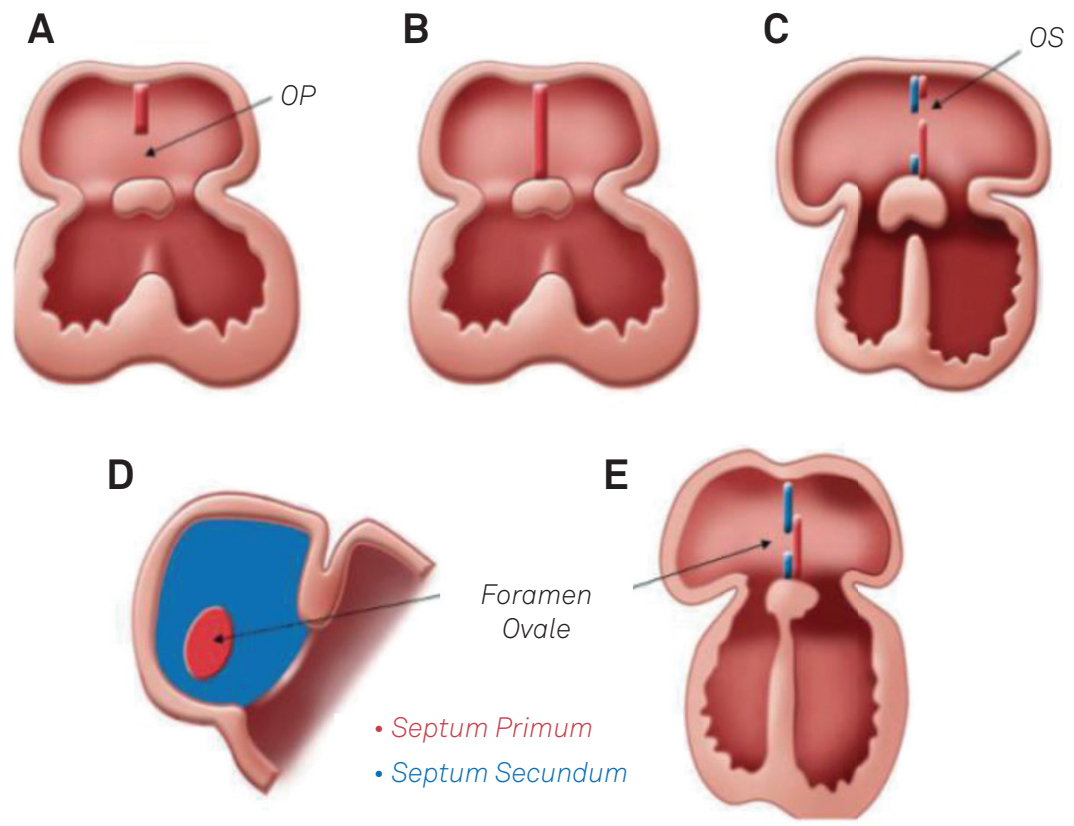

Figure. Development of the interatrial septum during fetal life ${ }^{1}$. (A) Initial formation of the septum primum (SP, in red color) directed to the endocardial cushions; the ostium primum (OP) allows ample communication between the atria. (B) Fusion of the SP with the endocardial cushions. (C) Another septum, the septum secundum (SS, in blue color, right-sided to the SP) begins to form. A second orifice, the ostium secundum (OS) develops in the superior portion of the SP. The SS gradually covers the SP. (D) Lateral view and (E) frontal view of the interatrial wall and the foramen ovale. 
thrombi are also more frequently found in cryptogenic stroke patients with a $\mathrm{PFO}^{12}$. However, the absence of a clear source of emboli does not exclude a paradoxical embolism, as small clots could easily pass through a moderate RLS and still cause the occlusion of important cerebral arteries.

Supraventricular arrhythmias such as atrial fibrillation (AF) and supraventricular tachycardia may cause strokes by themselves. Patients with a PFO and ASA are at higher risk for their development ${ }^{13,14}$. Associated conditions such as sleep apnea may contribute to this risk because of autonomic instability related to repeated episodes of hypoxia and adrenergic surges ${ }^{15,16}$. The relative equalization of pressures in the right and left atria during sleep favors local thrombus formation in patients with sleep apnea and PFO. The same mechanism can develop in individuals with chronic lung disease and cor pulmonale ${ }^{17}$.

A relationship between stroke and PFO should always be considered in the presence of favoring factors such as sleep apnea, cancer or other causes of thrombophilia. Patent foramen ovale is also more frequently found - and the severity of the related strokes increased - in strokes occurring the postoperative period ${ }^{18,19}$. In addition, a number of clinical findings are more frequent in patients with PFO than in other individuals with cryptogenic strokes (Table 1) ${ }^{17}$. Obviously, although heuristically helpful, all these findings may also be present in patients without a PFO and do not constitute proof of a causal relationship.

Acute treatment of stroke patients should not differ significantly in those with or without PFO. Intravenous thrombolysis and mechanical embolectomy should be considered whenever appropriate. Secondary preventive strategies include antiplatelet drugs, anticoagulants, and occlusion of the PFO either by surgery ${ }^{2}$ or, much more frequently, catheter-guided septal occlusion. Antiplatelet drugs, more commonly aspirin, were the usual drugs used in the medical arms (and in the intervention groups) of both negative and positive trials evaluating occlusion devices (see ahead). This is justified as these drugs may also lower the risk of recurrent stroke and severe cardiovascular events related

Table 1. Clinical clues of paradoxical embolism ${ }^{17}$. Although these findings are more frequent in cryptogenic stroke patients with a detectable patent foramen ovale (PFO), they also can be found in individuals without this anatomic variant.

\begin{tabular}{lcccc}
\hline Clinical finding & $\begin{array}{c}\text { PFO } \\
\text { (89) \% }\end{array}$ & $\begin{array}{c}\text { No PFO } \\
\text { (86) \% }\end{array}$ & p-value \\
\hline $\begin{array}{l}\text { History of deep venous thrombosis } \\
\text { or pulmonary embolism }\end{array}$ & 14 & 4 & 0.016 \\
Valsalva maneuver preceding onset & 15 & 6 & 0.042 \\
Recent prolonged travel & 12 & 3 & 0.018 \\
Waking up with deficit & 15 & 4 & 0.009 \\
History of migraine & 30 & 17 & 0.042 \\
Shortness of breath at onset & 15 & 7 & 0.093 \\
\hline (Number of patients in each group) & & &
\end{tabular}

to other undetected causes and atherosclerosis. In addition, they have a lower risk of hemorrhagic complications than anticoagulants. The antiplatelet regimen should be accompanied by an extensive evaluation and control of associated vascular risk factors such as hypertension, smoking and hyperlipidemia. Anticoagulants, almost exclusively warfarin, were optional in some trials, but the relatively low number of treated patients generally hampered any definite conclusion about their potential benefits ${ }^{20}$. A meta-analysis suggested that warfarin could be more efficient than antiplatelet drugs, reducing the risk of recurrent strokes by one quarter $^{21}$. Recently, a subgroup analysis of the NAVIGATE ESUS trial also found a non-significant decrease in risk - HR 0.54 (95\%CI, 0.22-1.36) - in PFO patients treated with rivaroxaban, compared with aspirin ${ }^{22}$. Other direct oral anticoagulants such as dabigatran (RESPECT ESUS) and apixaban (ATTICUS; ARCADIA) are being tested in trials of embolic stroke of unknown source (ESUS) ${ }^{23}$. In the recently published RE-SPECT ESUS trial, there was no significant reduction of recurrent strokes in patients treated with dabigatran as compared to low-dose aspirin ${ }^{24}$. There were significantly more clinically relevant but non-major bleeding events in the dabigatran group. No beneficial effects of anticoagulation were seen in 680 patients with PFO (circa 13\% of the patients). The use of DOACs has also been described in case reports and will probably increase in clinical practice ${ }^{22,25}$.

\section{TRIALS ON SEPTAL OCCLUSION}

Nonsurgical septal occlusion of septal defects was first tested in the 1970's decade ${ }^{26}$. A plethora of options exist, but they all share a basic mechanism involving radioscopic catheter guidance of two connected expandable discs to seal the interatrial communication from both sides.

In the decade since 2010, six prospective open trials comparing medical treatment and prosthetic sealing of PFO in young patients (up to 60 years) with cryptogenic stroke have been published. A long-term follow-up study of patients included in one of the first trials has also appeared in 2017. In all of these trials, patients submitted to endovascular treatment routinely received antiplatelet drugs (mostly low-dose aspirin) after a variable period (from a few days to three months) of double antiplatelet therapy with aspirin and a thienopyridine (usually clopidogrel).

\section{Negative trials}

\section{Closure 1 (2012) 27,28}

This trial was conducted in the USA and Canada comparing the STARFlex occlusion device (NMT Medical, Boston, USA) with a medical arm involving treatment with aspirin, warfarin or both (decision at the discretion of the principal investigator at each site). Patients could be included up to six 
months after stroke and were followed up for two years. More than one third of the patients had an associated ASA (interatrial mobility of $\geq 10 \mathrm{~mm}$ ) and more than half had a moderate (10-25 microbubbles) or large RLS. The intervention was unsuccessful in $11.6 \%$ of the patients, and incomplete closing - assessed by planned transesophageal echocardiography (TEE) at six months - occurred in $13.9 \%$. Only a few recurrent strokes occurred in both the endovascular and medical groups - 11 and 12 events, respectively (Table 2).

The inclusion criteria allowed individuals with classical lacunar infarcts and transient ischemic attacks (TIA) to be included, and a large percentage of patients had hypertension (34\% and $28 \%$ of the patients in the closure and medical treatment groups, respectively), and hyperlipidemia (47\% and 41\%). A follow-up study disclosed a high prevalence of alternative conditions favoring atherosclerosis in patients with recurrent strokes - high body mass index, diabetes, hypertension, ischemic heart disease and of AF (detected in $13.5 \%$ vs. $3.6 \%$ of patients with no further events) $)^{28,29,30}$.

\section{PC Trial (2013) $)^{31}$}

This trial was conducted in many European countries and in Canada, Brazil and Australia and compared treatment with the Amplatzer prosthesis (St. Jude Medical, Minnesota, USA) and medical therapy (choice at the discretion of the treating physician) with either antiplatelet drugs or warfarin (used in $30.5 \%$ of the patients at discharge). Most patients treated with antiplatelet drugs received aspirin $(77 \%)$, and a thienopyridine was given to all the others and to a few receiving double antiplatelet therapy. Patients could be included up to six months after a complete stroke (around $80 \%$ of inclusions), a TIA with a corresponding ischemic lesion in neuroimaging studies, or a peripheral embolism (less than 3\%). The initial TEE disclosed a large RLS (more than 20 microbubbles) in more than $20 \%$ of the patients, and an ASA in more than $20 \%$ of the patients (slight imbalances between groups). After a mean follow-up of 4.1 years, recurrent strokes occurred in one patient receiving the occlusion device and in five patients of the medical arm (HR 0.20, 95\%CI 0.02-1.72, p = 0.14).

It took 10 years to complete the patient inclusion in the PC Trial. There was a high prevalence of smoking, hypertension, and hyperlipidemia (circa 25\% each), and a large number of patients exited the study or were lost to follow-up (17.6\%). Twenty-eight patients in the medical group crossed over to receive an occlusion device - six in the first month and 22 subsequently. In addition, more than $10 \%$ of these patients received no antithrombotic therapy for long periods during the trial ${ }^{30}$. The procedure was unsuccessful in $4.1 \%$ of the patients and incomplete occlusion (moderate to large residual shunts) occurred in $4.1 \%$ more patients. Adverse effects attributed to the procedure included one patient with transient $\mathrm{AF}$ and two patients with groin

Table 2. Negative trials on patent foramen ovale closure published in 2012 and $2013^{27,28,31,32}$. A. Methods and main findings. B. Possible reasons for the negative results in each trial.

\begin{tabular}{|c|c|c|c|c|c|c|}
\hline \multicolumn{7}{|c|}{ A. Methods and main findings } \\
\hline Study (N) & Follow-up (in years) & \multirow{2}{*}{ Medical arm } & \multirow{2}{*}{ Primary Endpoint } & Events & \multirow{2}{*}{$\begin{array}{l}\text { Hazard } \\
\text { ratio }\end{array}$} & \multirow{2}{*}{$\mathrm{p}$-value } \\
\hline Prosthesis & Age & & & Prosthesis $\mathrm{x}$ medical & & \\
\hline Closure 1 & 2 & Aspirin & Stroke & $23 \times 29$ & & \\
\hline-909 & $(18-60 y)$ & Warfarin & TIA & (Cerebral infarct $12 \times 13$ ) & 0.78 & 0.37 \\
\hline STARflex & & Both & Death* & & & \\
\hline PC Trial & 4.1 & Aspirin & Death & $7 \times 11$ & \multirow{4}{*}{0.61} & \multirow{4}{*}{0.34} \\
\hline-414 & $(\leq 60 y)$ & Anticoagulants & Stroke & (Cerebral infarct $1 \times 5)$ & & \\
\hline \multirow[t]{2}{*}{ Amplatzer } & & & TIA & & & \\
\hline & & & $\begin{array}{l}\text { Peripheral } \\
\text { embolism }\end{array}$ & & & \\
\hline Respect (980) & 2.1 & $\begin{array}{c}\text { Aspirin } \pm \\
\text { dipyridamole }\end{array}$ & Fatal stroke & $9 \times 16$ & \multirow{3}{*}{0.49} & \multirow{3}{*}{0.08} \\
\hline \multirow[t]{2}{*}{ Amplatzer } & $(18-60 y)$ & Clopidogrel & Stroke & (Cerebral infarct $9 \times 16)$ & & \\
\hline & & Warfarin & Death & & & \\
\hline \multicolumn{7}{|c|}{ B. Possible reasons for negative results } \\
\hline Closure 1 & \multicolumn{6}{|c|}{$\begin{array}{l}\text { High percentage of unsuccessful closing; atherosclerosis and other causes; inclusion of patients with lacunar } \\
\text { infarcts; TIA as an endpoint; short follow-up }\end{array}$} \\
\hline PC Trial & \multicolumn{6}{|c|}{ Atherosclerosis; TIA as an endpoint; exits from study, crossover between groups; losses during follow-up } \\
\hline Respect & \multicolumn{6}{|c|}{ Delay to endovascular treatment; losses during follow-up; short follow-up } \\
\hline All Studies & \multicolumn{6}{|c|}{ Late inclusion in all (up to six months); few outcome events; no selection of high-risk patients } \\
\hline
\end{tabular}


hematomas. Additional patients with AF (in total six in the device group vs. two in the medical arm) and acute myocardial infarcts (two vs. one) were described.

\section{Respect (2013) $)^{32}$}

This trial was conducted in the USA and Canada, and compared the Amplatzer septal occlusion device (St. Jude Medical, Minnesota, USA) with antiplatelet or warfarin treatment in patients included up to six months after the index stroke. Recurrent strokes occurred in nine patients in the occlusion group and in 16 patients in the medical arm. Although the primary endpoint was negative, there was some heterogeneity of the treatment effect. Closure seemed more beneficial in patients with cortical infarcts, more indicative of embolic origin, large RLS or ASA; and when the comparison was restricted to patients receiving antiplatelet drugs. In addition, three infarcts in the Amplatzer group occurred before the planned endovascular procedure. Analyses according to time-to-stroke recurrence or restricted to patients who actually received the prosthesis also indicated benefit from the procedure.

There were major differences in dropout rates between patients receiving the prosthesis or not (9.2\% vs. 17.2\%), which the authors tried to compensate for statistically. There were at least 22 complications related to the procedure including two cases of pericardial tamponade, two cases of intracardiac thrombus formation (one in the prosthesis itself) and a single case each of pulmonary embolism and cardiac perforation. A control TEE done after six months detected an incomplete closure - defined as 10 or more microbubbles in the first three seconds after saline infusion - in $6.5 \%$ of the patients in the occlusion group.

All three trials showed a non-significant positive trend but could not prove benefit of the invasive treatment. The trials have important methodological differences and a number of reasons may explain the negative results including short follow-up (not in the PC Trial), inclusion of patients with lacunar infarcts, TIA or with probable atherosclerosis, high rates of unsuccessful closure, crossover between groups, exit, and dropout. They also share some problems, however. These include very slow randomization, late randomization and inclusion - up to six months after the index strokes - and the absence of inclusion criteria to increase the number of high-risk patients with ESUS, large shunts or associated ASA. This may have resulted in the lower-than-expected number of endpoint events in all trials, which reduced their power to show differential effects of the procedure.

\section{Positive trials}

Long-term follow-up results from an early trial and two new studies published in 2017 have led to a renewed interest in PFO closure. An additional smaller trial published in 2018 strengthened the impression of a positive impact of the procedure (Table 3).

\section{Respect Extended (2017) ${ }^{33}$}

After a longer follow-up period of 5.9 years, the authors found a significant reduction of cerebral infarcts in patients receiving a closure device. Secondary analyses again indicated a differential and positive effect in patients with ASA, large RLS and cortical infarcts. There was a reduction of recurrent strokes with an undetermined mechanism (as defined by either TOAST or ASCOD criteria) but not of those with other defined mechanisms. Slightly different numbers of adverse effects were reported including additional single cases of AF, pulmonary embolism and obligatory repeated intervention. Venous thromboembolism was more common in invasively-treated patients - e.g., HR for pulmonary embolism 3.48 (95\% CI, 0.98-12.34; $\mathrm{p}=0.04$ ). In the group of patients submitted to occlusion, the risk was especially high in those with previous episodes of venous thromboembolism.

Results from this exploratory analysis should be interpreted with caution for many reasons including its post hoc nature and the persistently high and unbalanced rates of loss to follow-up (33.3\% and $20.8 \%$ in the medical and intervention arms respectively).

\section{Reduce - Gore (2017) ${ }^{34}$}

This study was conducted in the USA, Canada, UK and Nordic countries, and randomized patients (2:1) to invasive treatment with two types of prosthesis (initially Helex and later Cardioform; Gore and Associates Inc., Delaware, USA) or to medical treatment with antiplatelet drugs - various regimens at the discretion of the local investigators. Patients were included up to six months after the index stroke, with the exclusion of those with small deep infarcts. Hypertension was present in $26 \%$ of the patients and a previous stroke or TIA in 13\% (slight imbalance between groups). A moderate shunt (defined as 6-25 microbubbles - 40.5\%) or large shunt (more that 25 microbubbles - 40.5\%) was present in most patients. There was no interaction between shunt size and the treatment effect.

No actual attempt to proceed with the intervention occurred in $6.3 \%$ of the patients randomized to the procedure. Incomplete closing was present in $24.4 \%$ after 12 months. Bleeding episodes - defined as severe or not by local investigators - occurred frequently (double antiplatelet therapy obligatory for only three days) and there were some cases of device dislodgement and cardiac thrombus formation. Atrial fibrillation developed in $6.6 \%$ of patients after the intervention, and additional single cases of cardiac tamponade and aortic dissection occurred.

This study had many important flaws. Researchers from the sponsoring company were directly involved in the conception and statistical planning, and analysis of the trial. The primary endpoint was changed during the study to include a co-primary endpoint (infarcts detected in MRI) as "other trials of PFO closure reported lower-than-expected risks of stroke in medically-treated patients." In addition, a 
Table 3. Positive trials on patent foramen ovale closure $20,33,34,35$. A. Methods and main findings. B. Closure devices used, definitions of high-risk patients, number needed to treat to prevent one endpoint event, selected endpoints including strokes in medical groups, adverse effects related to the procedure and closure device, and incomplete closure.

\begin{tabular}{|c|c|c|c|c|c|c|}
\hline \multicolumn{7}{|c|}{ A. Methods and main findings } \\
\hline \multirow{2}{*}{ Study (N) } & $\begin{array}{c}\text { Follow-up in } \\
\text { years }\end{array}$ & \multirow{2}{*}{ Medical arm } & \multirow{2}{*}{ Primary endpoint } & Events & \multirow{2}{*}{$\begin{array}{l}\text { Hazard } \\
\text { ratio }\end{array}$} & \multirow{2}{*}{$\mathrm{p}$-value } \\
\hline & (Age) & & & Prosthesis $\mathrm{x}$ medical & & \\
\hline \multirow[t]{2}{*}{ REDUCE - Gore (664) } & & $\begin{array}{c}\text { Aspirin } \pm \\
\text { Dipyridamole }\end{array}$ & & & \multirow[t]{2}{*}{0.23} & \multirow[t]{2}{*}{0.002} \\
\hline & $(18-59)$ & Clopidogrel & Stroke on MRI & $(\mathrm{MRI} 22 \times 20)$ & & \\
\hline Close & 5.3 & Aspirin mainly & \multirow{2}{*}{ Stroke } & $0 \times 14 \times 3$ & \multirow{2}{*}{0.03} & \multirow{2}{*}{$<0.001$} \\
\hline-663 & $(16-60)$ & Warfarin mainly & & $(1: 1: 1)$ & & \\
\hline RESPECT & 5.9 & Aspirin & Fatal stroke & $18 \times 28$ & \multirow{3}{*}{0.55} & \multirow{3}{*}{0.046} \\
\hline \multirow{2}{*}{$\begin{array}{l}\text { Extended } \\
-980\end{array}$} & $(18-60)$ & Warfarin & Stroke & (Cerebral infarct $18 \times 28$ & & \\
\hline & & & Early death & Cryptogenic stroke $10 \times 23$ ) & & \\
\hline \multirow{3}{*}{ DEFENCE (120) } & 2.8 & Aspirin & Stroke & \multirow{3}{*}{$0 \times 6$} & \multirow{3}{*}{0.13} & \multirow{3}{*}{0.013} \\
\hline & $(? \mathrm{M} \mathrm{51})^{\star}$ & Anticoagulants & Vascular death & & & \\
\hline & & & Severe bleeding & & & \\
\hline \multicolumn{7}{|c|}{ B. Enrichment protocols, NNT and selected endpoints } \\
\hline Study (prosthesis) & High risk & NNT & $\begin{array}{l}\text { Strokes in medical } \\
\text { arm }\end{array}$ & $\begin{array}{l}\text { Procedure adverse } \\
\text { effects** }\end{array}$ & $\begin{array}{l}\text { Incomplete } \\
\text { closing** }\end{array}$ & \\
\hline REDUCE & $\begin{array}{c}\text { ? (shunt }>5 \\
\text { microbubbles in } \\
81 \%)\end{array}$ & \multirow[t]{2}{*}{12} & \multirow[t]{2}{*}{17} & \multirow[t]{2}{*}{ (AF in 29 patients - 6.6\%) } & \multirow[t]{2}{*}{$24 \%$} & \\
\hline (Gore) & 28 & & & & & \\
\hline \multirow{2}{*}{$\begin{array}{l}\text { CLOSE } \\
\text { (many) }\end{array}$} & $\begin{array}{c}\text { Shunt (30 } \\
\text { microbubbles) }\end{array}$ & \multirow[t]{2}{*}{20} & 14 & 14 & \multirow[t]{2}{*}{16} & \\
\hline & ASA (10 mm) & & (3 on anticoagulant) & (AF/flutter in 11) & & \\
\hline $\begin{array}{l}\text { RESPECT extended } \\
\text { (Amplatzer) }\end{array}$ & No & 42 & 18 & 25 & $30(32 ?)^{\star \star \star}$ & \\
\hline \multirow{3}{*}{ DEFENCE (Amplatzer) } & $\begin{array}{l}\text { ASA }(15 \mathrm{~mm}) \text {, } \\
\text { hypermobility } \\
(10 \mathrm{~mm})\end{array}$ & \multirow{3}{*}{10} & 5 & 2 & \multirow{3}{*}{4} & \\
\hline & $\begin{array}{l}\text { PFO size (2 mm } \\
\text { Valsalva) }\end{array}$ & & (hypermobility/ & $(A F$ in 2$)$ & & \\
\hline & & & ASA in 4) & & & \\
\hline
\end{tabular}

N: number of patients; M: mean; MRI: new visible lesions in magnetic resonance imaging; NNT: number needed to treat: number of patients that need to be treated to avoid one endpoint event; ASA: atrial septal aneurysm; PFO: patent foramen ovale; AF: atrial fibrillation. *The age span is not described (mean age 54 and 49 years in the medical and closure groups respectively); $* \star$ Adverse effects and incomplete closure are presented either in \% or N; $* \star$ Slightly different figures in the initial and follow-up publications.

new type of closing device was substituted during the trial without previous planning or further explanation; and the planned final MRI at 24 months was done in only 560 of the 664 study patients.

\section{Close (2017) 20}

This complex design study was held in France and Germany and involved extra randomizations of individuals with a contraindication to any of the three study arms antiplatelet treatment (aspirin in 96\%, 10\% of patients with added clopidogrel), anticoagulant treatment (warfarin in 93\%) or PFO closure. Patients were randomized only if they exhibited a large RLS ( $>30$ microbubbles within three cardiac cycles after right atrium opacification) or an associated ASA (septum primum excursion $>10 \mathrm{~mm}$ ) in TEE. Eleven types of occlusion devices available in Europe were used, with $59 \%$ of the patients treated with Amplatzer devices (AGA Medical Corp./St. Jude Medical) ${ }^{20}$. Holter studies or a minimum 24-hour period of external cardiac monitoring was obligatory. Hypertension was less prevalent than in other studies (circa 10\%), but current smoking was highly prevalent (29\%).

The primary endpoint of recurrent stroke did not occur in any patient in the closure group. This led to a highly significant beneficial effect. More recurrent strokes in the antiplatelet treatment group occurred in individuals with ASA (9/74) than in those with large shunts but no ASA (5/161). No formal statistical comparison between the closure and anticoagulant treatment groups was possible. Anticoagulant treatment was associated with a non-significant reduction 
in stroke rates compared with the antiplatelet regimen: HR 0.44 (95\%CI, 0.11-1.48).

The original plan was to study 900 patients but slower than expected randomization rates led to the early termination of inclusion after eight years. Incomplete closure (more than 10 microbubbles in the control TEE 10 months after the procedure) occurred in 16 patients (7\%). Severe adverse events related to the procedure or the devices included two episodes of severe bleeding, 10 cases of AF (most with early and permanent reversal) and additional cases of supraventricular tachycardia (two patients) and atrial flutter (one patient). No exploratory analysis according to the type of prosthesis used was presented.

\section{Defense-PFO Trial (2018) $)^{35}$}

This smaller study was held in South Korea and randomized 120 patients to PFO occlusion with the Amplatzer device (double antiplatelet therapy during the first six months) and antithrombotic treatment with aspirin (clopidogrel or cilostazol added in more than half) or warfarin (in 20-25\% of the patients, over the period of the trial). Inclusion criteria included the obligatory presence of an ASA ( $\geq 15 \mathrm{~mm}$ septal protrusion), septal hypermobility (phasic septal excursion $\geq 10 \mathrm{~mm}$ ), or a large PFO ( $\geq 2 \mathrm{~mm}$ separation between septum primum and secundum during the Valsalva maneuver; mean \pm S.D. $3.2 \pm 1.1 \mathrm{~mm}$ ). No event of the primary endpoint occurred in the device group, and this led to a significant beneficial effect of the invasive treatment and a relatively low number needed to treat (NNT). Four of the five strokes that occurred in the medical arm occurred in patients with ASA or atrial hypermobility.

The inclusion process terminated early, after the publication of the CLOSE trial and an interim analysis. Two cases of AF and a single case each of pericardial effusion and pseudoaneurysm at the puncture site occurred in patients receiving the device. An early TEE revealed a significant residual shunt $(\geq 10 \mathrm{~mm}$ ) in four of the 60 treated patients.

The six published trials on PFO closure all had an open design. They had varied inclusion criteria, involved many types of occlusion devices and medical therapies, and the larger ones could not prevent a high number of losses to follow-up. The longer follow-up of patients reported by the RESPECT investigators and the new trials published in 2017 and 2018 found statistically significant differences favoring PFO closure. A beneficial effect had already been suggested by positive trends in the earlier trials.

The publication of these positive trials could reverse the skepticism surrounding the invasive treatment of PFO in patients with cerebral infarcts. Their results, however, do not indicate that all stroke patients with PFO should receive a closure device. All of them studied only young individuals ( $\leq 60$ years). Two positive trials - CLOSE and DEFENSE-PFO - involved a better selection of cryptogenic stroke patients and the inclusion of a larger number of high-risk patients with ASA or large RLS. A relatively-high prevalence of highrisk patients was also present in the CLOSURE trial - with negative results. The REDUCE trial included a high percentage of patients with shunts that would not usually be considered moderate but were so classified by the authors.

Despite this better selection, the two new trials published in 2017 and the RESPECT longer follow-up study all disclosed a high NNT - 20-42 (Table 3B). In addition, the number of recurrent strokes in medically-treated patients was always small and, in fact, comparable to the number of adverse events. Atrial fibrillation occurred in 3-7\% of treated patients. It was usually reversed without difficulty but led to a temporary need for anticoagulation.

Septal occlusion is a relatively safe procedure. However, vascular and cardiac complications and rare severe bleeding should be expected. Late severe complications are also reported $^{36}$. Finally, although PFO closure is relatively easy, it is frequently incomplete and the actual therapeutic value of a partial closure is not clear.

\section{NOW WHAT?}

Patent foramen ovale occlusion may provide a definite preventive method after a cerebral infarct. Patients sometimes mention the psychological comfort provided by this rational idea as an additional reason to intervene. There are, however, a number of arguments against PFO closure as a routine therapeutic choice. These include the risks associated with both the procedure and the occlusion devices and the high NNT found in most positive trials. It should also be remembered that many unapparent causes may be the real culprits and sometimes are only evident after extensive and repeated investigation and prolonged cardiac rhythm monitoring ${ }^{29,30,37}$. Electrocardiographic examinations by repeated Holter monitoring or implanted devices may detect unapparent AF after stroke, leading to earlier oral anticoagulation ${ }^{37,38}$.

The initial workout is usually not able to exclude with confidence alternative causes in patients with stroke and PFO and should not be seen as definite ${ }^{29,30}$. There should be special concern in individuals over 55-60 years, with classical cardiovascular risk factors or with small subcortical infarcts. Even in patients without any obvious alternative cause, however, the presence of a PFO suggests a pathogenic relationship but does not prove causality. This was well documented by the researchers who developed the risk of paradoxical embolism (RoPE) score ${ }^{4}$ (Table 4). In this large study, as expected, younger patients with cortical infarcts and no other risk factors exhibited a higher probability of harboring a $\mathrm{PFO}$ (Table 4A). The PFO attributable risk increased in direct proportion. This, however, was not associated with an increasing risk of recurrence. Cryptogenic stroke patients with the highest RoPE scores - no associated factors suggesting 
Table 4. The RoPE Score ${ }^{4}$. A. Criteria and attributed points in the assessment of cryptogenic stroke patients. B. The probability of finding a patent foramen ovale (PFO) and the PFO-attributable fraction increases with increasing RoPE scores. However, the risk of recurrence declines in those patients with a PFO and the highest RoPE scores (more "pure" patients).

\begin{tabular}{|c|c|c|c|}
\hline \multicolumn{4}{|c|}{ A. Characteristics and attributed points. } \\
\hline Characteristic & Points & \multicolumn{2}{|c|}{ RoPE Score (0-10) } \\
\hline No history of hypertension & 1 & & \\
\hline No history of diabetes & 1 & & \\
\hline No history of stroke or TIA & 1 & & \\
\hline Non-smoker & 1 & & \\
\hline Cortical infarct on imaging & 1 & & \\
\hline \multicolumn{4}{|l|}{ Age, in years } \\
\hline $18-29$ & 5 & & \\
\hline $30-39$ & 4 & & \\
\hline $40-49$ & 3 & & \\
\hline $50-59$ & 2 & & \\
\hline $60-69$ & 1 & & \\
\hline$\geq 70$ & 0 & & \\
\hline \multicolumn{4}{|l|}{ Total Score (sum of all points) } \\
\hline \multicolumn{4}{|c|}{$\begin{array}{l}\text { B. Probability of finding a PFO and the PFO attributable fraction in cryptogenic stroke, and the risk of stroke recurrence in patients } \\
\text { with both cryptogenic stroke and PFO. }\end{array}$} \\
\hline Cryptogenic stroke & & & $\begin{array}{l}\text { Cryptogenic stroke plus } \\
\text { PFO }\end{array}$ \\
\hline RoPE Score & PFO prevalence, \% & $\begin{array}{l}\text { PFO attributable } \\
\text { fraction, \% }\end{array}$ & $\begin{array}{l}\text { Recurrence risk in two } \\
\text { years, \% }\end{array}$ \\
\hline $0-3$ & 23 & 0 & 20 \\
\hline 4 & 35 & 38 & 12 \\
\hline 5 & 34 & 34 & 7 \\
\hline 6 & 47 & 62 & 8 \\
\hline 7 & 54 & 72 & 6 \\
\hline 8 & 67 & 84 & 6 \\
\hline $9-10$ & 73 & 88 & 2 \\
\hline
\end{tabular}

RoPE: risk of paradoxical embolism; TIA: transient ischemic attack; PFO: patent foramen ovale.

alternative causes - in fact exhibited the lowest risk of stroke recurrence (Table 4B). This should be considered when evaluating the ideal treatment of PFO after cerebral infarct.

In parallel to negative findings, absence of criteria for other causes of cerebral infarcts, positive evidence of the importance of PFO should be searched for routinely. This includes clinical and laboratory findings and the particulars of ultrasound examinations. Genetic causes of thrombophilia, the use of oral hormonal contraceptives, pregnancy, recent surgery or prolonged (more than four hours) travel, neoplastic diseases or any previous or present evidence of venous thromboembolism should be seen as underlying conditions predisposing to thrombosis and hence to paradoxical embolism. Additional clinical clues suggesting the presence of a PFO and paradoxical embolism include stroke occurring at high altitudes or related to diving and decompression, a history of migraine, stroke onset shortly after a
Valsalva maneuver (straining, weight lifting, sexual intercourse, coughing etc.), during sleep (suggesting underlying sleep apnea) or associated with dyspnea ${ }^{17}$ (Table 1).

Even more importantly, there is now clear evidence from the positive PFO closure trials that the presence of ASA or of a large PFO - assessed anatomically or by the degree of RLS - increases the risk of recurrent stroke and helps predict a better evolution after PFO closure. The risk may be particularly high in untreated patients with associated ASA ${ }^{20,32,35}$. The presence of ASA is also associated with a higher chance of finding a large RLS during the passive phase of the saline test $^{17}$ and with AF during workout ${ }^{13,14}$.

Echocardiography - especially TEE - and transcranial Doppler (TCD) are complementary in the evaluation of PFO patients. In patients with a hemispheric infarct, for instance, the finding of microemboli in a strictly ipsilateral pattern during prolonged TCD monitoring at rest, is highly 
suggestive of a distal origin of emboli such as unrecognized internal carotid artery disease. Although TEE is usually considered highly sensitive for the detection of PFO, it may, in fact, miss many cases ${ }^{39,40}$. The efficiency of the Valsalva maneuver can be demonstrated in TCD by a decrease in flow velocity of the middle cerebral artery (minimum 25\%). In contrast, the maneuver is less efficient during TEE due to routine light sedation. The degree of RLS is more objectively evaluated by TCD monitoring during the first 60 seconds after the infusion of agitated saline than by TEE. In addition, the degree of RLS as estimated by TCD may better predict the risk of recurrence in the first year or two after an index stroke ${ }^{40,41}$. Patients in whom a grade 3 (31-100 microbubbles) or higher RLS is detected exhibit an especially high risk $^{40}$.

Although the recent positive trials suggest a lower efficiency of antiplatelet therapy in high-risk patients with PFO, treatment with a double antiplatelet regimen, as presently indicated in most acute ischemic stroke patients, is a reasonable option while the initial diagnostic workup is completed. A single antiplatelet regimen may be substituted after many weeks if a longer period before definite conclusions is necessary. Anticoagulant therapy should be initiated in patients with detected paroxysmal AF during the evaluation process or after the procedure, as it is not contraindicated in patients receiving a closing device. Warfarin is the drug used in almost all trials and constitutes the usual choice, but experience with the direct oral anticoagulants is now being reported and will probably increase in the near future.

\section{CONCLUSIONS}

There is now enough scientific evidence to offer PFO closure to young patients with cryptogenic stroke and associated ASA or large RLS as determined by TEE and TCD. The minimum investigation should also include Holter monitoring and a thorough evaluation of the arterial supply to the brain, including the aortic arch, by either magnetic resonance angiography or angiotomography.

All other patients with cryptogenic cerebral infarcts and PFO should have an individualized decision after discussion of the large NNT and the risks associated with the procedure and occluding devices. Closure of a PFO is an elective procedure and the final decision regarding the therapeutic choice should usually be made only after extensive investigation including repeated prolonged Holter monitoring. Additional vascular risk factors should always be managed appropriately. Large cortical infarcts are more likely to be embolic, while small deep infarcts strongly suggest alternative processes including atherosclerosis and intracranial arterial disease (arteritis etc.). Although the origin of small emboli passing through a PFO or other cardiac defect and leading to a clinically significant cerebral infarct may frequently be unapparent, evidence of venous thromboembolism and vascular anomalies favoring it in the lower limbs and pelvis should be routinely sought.

There are little hard data to support the choice of one or other closure device but the Amplatzer prosthesis may be associated with a lower frequency of unsuccessful implantation and of AF. Finally, local experience with the invasive procedure should be a prerequisite.

\section{References}

1. Cruz-González I, Solis J, Inglessis-Azuaje I, Palacios IF. [Patent foramen ovale: current state of the art]. Rev Esp Cardiol. 2008 Jul;61(7):738-51. Spanish

2. Patten BM. The closure of the foramen ovale. Am J Anat. 1931;48(1):19-44. https://doi.org/10.1002/aja.1000480104

3. Chamié F, Chamié D, Ramos S, Tress JC, Victer R. Fechamento percutâneo do forame oval patente. Rev Bras Cardiol Invasiva. 2005;13(3):185-97

4. Kent DM, Ruthazer R, Weimar C, Mas JL, Serena J, Homma S, et al. An index to identify stroke-related vs incidental patent foramen ovale in cryptogenic stroke. Neurology. 2013 Aug;81(7):619-25. https://doi.org/10.1212/WNL.0b013e3182a08d59

5. Kim MJ, Jung HO. Anatomic variants mimicking pathology on echocardiography: differential diagnosis. J Cardiovasc Ultrasound. 2013 Sep;21(3):103-12. https://doi.org/10.4250/jcu.2013.21.3.103

6. Tarelho LS, Milani M, Milani JG, Suero AR, Martins BH, Bertipaglia H. Forame Oval Patente e mergulho: controvérsias e recomendações: uma revisão sobre o assunto. Rev DERC. 2015;21(1):20-4.

7. Tariq N, Tepper SJ, Kriegler JS. Patent foramen ovale and migraine: closing the debate: a review. Headache. 2016 Mar;56(3):462-78. https://doi.org/10.1111/head.12779

8. Overell JR, Bone I, Lees KR. Interatrial septal abnormalities and stroke: a meta-analysis of case-control studies. Neurology. 2000 Oct;55(8):1172-9. https://doi.org/10.1212/WNL.55.8.1172
9. Mazzucco S, Li L, Binney L, Rothwell PM. Prevalence of patent foramen ovale in cryptogenic transient ischaemic attack and non-disabling stroke at older ages: a population-based study, systematic review, and meta-analysis. Lancet Neurol. $2018 \mathrm{Jul}$;17(7):609-17. https://doi.org/10.1016/S1474-4422(18)30167-4

10. Hutchinson EC, Acheson EJ. Strokes: natural history, pathology and surgical treatment. In: Walton J, editor. Major problems in neurology. Philadelphia: W.B. Saunders; 1975. Vol. 4.

11. Cramer SC, Rordorf G, Maki JH, Kramer LA, Grotta JC, Burgin WS, et al. Increased pelvic vein thrombi in cryptogenic stroke: results of the Paradoxical Emboli from Large Veins in Ischemic Stroke (PELVIS) study. Stroke. 2004 Jan;35(1):46-50. https://doi.org/10.1161/01.STR.0000106137.42649.AB

12. Osgood M, Budman E, Carandang R, Goddeau RP Jr, Henninger N. Prevalence of pelvic vein pathology in patients with cryptogenic stroke and patent Foramen Ovale undergoing MRV Pelvis. Cerebrovasc Dis. 2015;39(3-4):216-23. https://doi.org/10.1159/000376613

13. Berthet K, Lavergne T, Cohen A, Guize L, Bousser MG, Le Heuzey JY, et al. Significant association of atrial vulnerability with atrial septal abnormalities in young patients with ischemic stroke of unknown cause. Stroke. 2000 Feb;31(2):398-403. https://doi.org/10.1161/01.STR.31.2.398 
14. Chubb H, Whitaker J, Williams SE, Head CE, Chung NA, Wright $\mathrm{MJ}$, et al. Pathophysiology and management of arrhythmias associated with atrial septal defect and patent foramen ovale. Arrhythm Electrophysiol Rev. 2014 Nov;3(3):168-72. https://doi.org/10.15420/aer.2014.3.3.168PMID:26835086

15. Linz D, McEvoy RD, Cowie MR, Somers VK, Nattel S, Lévy P, et al. Associations of obstructive sleep apnea with atrial fibrillation and continuous positive airway pressure treatment: a review. JAMA Cardiol. 2018 Jun;3(6):532-40. https://doi.org/10.1001/jamacardio.2018.0095

16. Congrete S, Bintvihok M, Thongprayoon C, Bathini T, Boonpheng B, Sharma K, et al. Effect of obstructive sleep apnea and its treatment of atrial fibrillation recurrence after radiofrequency catheter ablation: A meta-analysis. J Evid Based Med. 2018 Aug;11(3):145-51. https://doi.org/10.1111/jebm.12313

17. Ozdemir AO, Tamayo A, Munoz C, Dias B, Spence JD. Cryptogenic stroke and patent foramen ovale: clinical clues to paradoxical embolism. J Neurol Sci. 2008 Dec;275(1-2):121-7. https://doi.org/10.1016/j.jns.2008.08.018

18. Perfetti DC, Chughtai M, Boylan MR, Naziri Q, Maheshwari AV, Mont MA. Atrial septal defect increases the risk for stroke after total hip arthroplasty. J Arthroplasty. 2017 Oct;32(10):3152-6. https://doi.org/10.1016/j.arth.2017.05.006

19. Ng PY, Ng AK, Subramaniam B, Burns SM, Herisson F, Timm FP, et al. Association of preoperatively diagnosed patent foramen ovale with perioperative ischemic stroke. JAMA. 2018 Feb;319(5):452-62. https://doi.org/10.1001/jama.2017.21899

20. Mas JL, Derumeaux G, Guillon B, Massardier E, Hosseini H, Mechtouff L, et al. Patent Foramen ovale closure or anticoagulation vs. antiplatelets after stroke. N Engl J Med. 2017 Sep;377(11):1011-21. https://doi.org/10.1056/NEJMoa1705915

21. Kent DM, Dahabreh IJ, Ruthazer R, Furlan AJ, Weimar C, Serena $\mathrm{J}$, et al. Anticoagulant vs. antiplatelet therapy in patients with cryptogenic stroke and patent foramen ovale: an individual participant data meta-analysis. Eur Heart J. 2015 Sep;36(35):2381-9. https://doi.org/10.1093/eurheartj/ehv252

22. Kasner SE, Swaminathan B, Lavados P, Sharma M, Muir K, Veltkamp R, et al. Rivaroxaban or aspirin for patent foramen ovale and embolic stroke of undetermined source: a prespecified subgroup analysis from the Navigate Esus trial. Lancet Neurol. 2018 Dec;17(12):1053-106. https://doi.org/10.1016/S1474-4422(18)30319-3

23. Tomek A. Embolic stroke of undetermined source (ESUS). CNS. 2018;4(1):92-7.

24. Diener HC, Sacco RL, Easton JD, Granger CB, Bernstein RA, Uchiyama S, Kreuzer J, Cronin L, Cotton D, Grauer C, Brueckmann M, Chernyatina M, Donnan G, Ferro JM, Grond M, Kallmünzer B, Krupinski J, Lee BC, Lemmens R, Masjuan J, Odinak M, Saver JL, Schellinger PD, Toni D, Toyoda K; RE-SPECT ESUS Steering Committee and Investigators. Dabigatran for Prevention of Stroke after Embolic Stroke of Undetermined Source. N Engl J Med. 2019 May 16;380(20):1906-1917. doi:10.1056/NEJMoa1813959.

25. Chitose T, Yamashita T, Miura M, Matsuyama K. Complete response to rivaroxaban in a case of invaginated thrombus thought to have extended through a patent foramen ovale with an accompanying pulmonary embolism. J Cardiol Cases. 2016 Jun;14(3):65-8. https://doi.org/10.1016/j.jccase.2016.03.020

26. Mills NL, King TD. Nonoperative closure of left-to-right shunts. J Thorac Cardiovasc Surg. 1976 Sep;72(3):371-8.

27. Furlan AJ, Reisman M, Massaro J, Mauri L, Adams H, Albers GW, et al. Study design of the CLOSURE I Trial: a prospective, multicenter, randomized, controlled trial to evaluate the safety and efficacy of the STARFlex septal closure system versus best medical therapy in patients with stroke or transient ischemic attack due to presumed paradoxical embolism through a patent foramen ovale. Stroke. 2010 Dec;41(12):2872-83. https://doi.org/10.1161/STROKEAHA.110.593376

28. Furlan AJ, Reisman M, Massaro J, Mauri L, Adams H, Albers GW, et al. Closure or medical therapy for cryptogenic stroke with patent foramen ovale. N Engl J Med. 2012 Mar;366(11):991-9. https://doi.org/10.1056/NEJMoa1009639

29. Elmariah S, Furlan AJ, Reisman M, Burke D, Vardi M, Wimmer NJ, et al. Predictors of recurrent events in patients with cryptogenic stroke and patent foramen ovale within the CLOSURE I (Evaluation of the STARFlex Septal Closure System in Patients With a Stroke and/or Transient Ischemic Attack Due to Presumed Paradoxical Embolism Through a Patent Foramen Ovale) trial. JACC Cardiovasc Interv. 2014 Aug;7(8):913-20. https://doi.org/10.1016/j.jcin.2014.01.170

30. Abou-Chebl A. The paradox of paradoxical embolism and recurrent stroke. JACC Cardiovasc Interv. 2014 Aug;7(8):921-2. https://doi.org/10.1016/j.jcin.2014.03.006

31. Meier B, Kalesan B, Mattle HP, Khattab AA, Hildick-Smith D, Dudek D, et al. Percutaneous closure of patent foramen ovale in cryptogenic embolism. N Engl J Med. 2013 Mar;368(12):1083-91. https://doi.org/10.1056/NEJMoa1211716

32. Carroll JD, Saver JL, Thaler DE, Smalling RW, Berry S, MacDonald $L A$, et al. Closure of patent foramen ovale versus medical therapy after cryptogenic stroke. N Engl J Med. 2013 Mar;368(12):1092-100. https://doi.org/10.1056/NEJMoa1301440

33. Saver JL, Carroll JD, Thaler DE, Smalling RW, MacDonald LA, Marks DS, et al. Long-Term Outcomes of Patent Foramen Ovale Closure or Medical Therapy after Stroke. N Engl J Med. 2017 Sep;377(11):1022-32. https://doi.org/10.1056/NEJMoa1610057

34. Søndergaard L, Kasner SE, Rhodes JF, Andersen G, Iversen HK, Nielsen-Kudsk JE, et al. Patent foramen ovale closure or antiplatelet therapy for cryptogenic stroke. N Engl J Med. 2017 Sep;377(11):1033-42. https://doi.org/10.1056/NEJMoa1707404

35. Lee PH, Song JK, Kim JS, Heo R, Lee S, Kim DH, et al. Cryptogenic stroke and high-risk patent foramen ovale: the DEFENSEPFO Trial. J Am Coll Cardiol. 2018 May;71(20):2335-42. https://doi.org/10.1016/j.jacc.2018.02.046

36. Motreff P, Dauphin C, Souteyrand G. Cardiac perforation and tamponade 3 months after transcatheter PFO closure by STARFlex device: A case report. Catheter Cardiovasc Interv. 2008 Feb;71(3):412-6. https://doi.org/10.1002/ccd.21339

37. Sanna T, Diener HC, Passman RS, Di Lazzaro V, Bernstein RA, Morillo CA, et al. Cryptogenic stroke and underlying atrial fibrillation. N Engl J Med. 2014 Jun;370(26):2478-86. https://doi.org/10.1056/NEJMoa1313600

38. Wachter R, Gröschel K, Gelbrich G, Hamann GF, Kermer P, Liman $J$, et al. Holter-electrocardiogram-monitoring in patients with acute ischaemic stroke (Find-AFRANDOMISED): an open-label randomised controlled trial. Lancet Neurol. 2017 Apr;16(4):282-90. https://doi.org/10.1016/S1474-4422(17)30002-9

39. Wessler BS, Kent DM, Thaler DE, Ruthazer R, Lutz JS, Serena J. The RoPE score and right-to-left shunt severity by transcranial doppler in the CODICIA Study. Cerebrovasc Dis. 2015;40(1-2):52-8. https://doi.org/10.1159/000430998

40. Tobe J, Bogiatzi C, Munoz C, Tamayo A, Spence JD. Transcranial Doppler is complementary to echocardiography for detection and risk stratification of patent foramen ovale. Can J Cardiol. 2016 Aug;32(8):986.e9-16. https://doi.org/10.1016/j.cjca.2015.12.009

41. Anzola GP, Zavarize P, Morandi E, Rozzini L, Parrinello G. Transcranial Doppler and risk of recurrence in patients with stroke and patent foramen ovale. Eur J Neurol. 2003 Mar;10(2):129-35. https://doi.org/10.1046/j.1468-1331.2003.00561.x 